\title{
Bile Salt Metabolism in Infants and Children after Protracted Infantile Diarrhea
}

\author{
JAMES E. HEUBI ${ }^{(32)}$ AND WILLIAM F. BALISTRERI \\ Division of Gastroenterology, Department of Pediatrics, University of Cincinnati, College of Medicine,
}

Cincinnati, Ohio, USA

\begin{abstract}
Summary
Ten infants and children (mean age, 44 months), who had recovered from protracted infantile diarrhea with no sequelae, underwent detailed investigations of cholate metabolism using the isotope dilution technique. Cholate pool size was $1011 \pm 73 \mathrm{mg} /$ $\mathrm{m}^{2},(\overline{\mathrm{x}} \pm$ S.E. $)$, synthetic rate was $358 \pm 58 \mathrm{mg} / \mathrm{m}^{2} /$ day, and the fractional turnover rate was $0.359 \pm 0.049$ days $^{-1}$. Pool size, uncorrected for body surface area differences, was shown to increase directly with body size $(r=0.827 ; P=0.002)$ and age $(r$ $=0.724 ; P=0.009$ ). The fractional turnover rate varied inversely with age $(r=-0.656 ; P=0.02)$, surface area $(r=-0.642 ; P=$ $0.023)$, and pool size $(r=-0.703 ; P=0.012)$ and directly with synthesis $(r=0.878 ; P<0.001)$. Infants and children have an intact enterohepatic circulation of cholate; the pool size and the mechanisms which regulate synthesis are similar to adults. The progressive enlargement of pool size with age is associated with an agerelated increase in intraluminal bile salt concentrations which ensures normal intraluminal fat digestion and solubilization.
\end{abstract}

\section{Speculation}

At birth, term and premature infants have contracted primary bile salt pools which contribute to the observed steatorrhea of the newborn. Rapid expansion of the cholic acid pool size in the first months of life demonstrated in the present study increases intraluminal bile salt concentrations which facilitates intraluminal fat digestion, but the mechanisms modulating the expansion in the neonate have been largely unexplored. Pool enlargement and enhanced fecal sterol excretion may be a homeostatic response of the developing organism to rising serum and hepatic cholesterol concentrations.

Characterization of the enterohepatic circulation of bile acids by the isotopic dilution technique has become a standard research tool in gastroenterology (12). This method has provided valuable information regarding bile acid metabolism in adults in health and in diseases such as cholelithiasis, cholestasis, cirrhosis, and hyperlipidemia $(2,14,24-26)$. Studies in infants and children have been limited $(22,27-29)$. Similar studies of bile salt metabolism in infants and children are needed because alterations in bile salt metabolism may contribute to the inefficient fat absorption seen in newborns. In addition, adaptive changes occurring in the first months of life may affect sterol metabolism; therefore, studies in infants and children may improve our understanding of maturational changes in bile salt metabolism.

Previous studies from our laboratory in children with chronic diarrhea in infancy have shown accelerated fecal excretion of orally administered [carboxyl $-{ }^{14} \mathrm{C}$ ]cholic acid in two infants with congenital diarrhea or diarrhea beginning in the first wk of life and four children with neonatal ileal resection (1). Therefore, we undertook a prospective study of all infants with diarrhea and/or steatorrhea beginning in the first months of life who required parenteral alimentation for nutritional support to determine if any of these children had specific abnormalities of cholate metabolism after recovery from the acute phase of their illnesses. In the course of these studies, two unrelated boys with refractory diarrhea from birth were found to have a specific congenital defect in ileal active bile salt transport which produced pathophysiologic alterations in bile salt metabolism similar to those seen in children and adults with terminal ileal resection. They comprise the subject of additional reports $(8,9)$.

In the present study, we describe the measurement of cholic acid metabolism by the isotopic dilution technique in 10 infants and children who had recovered from refractory infantile diarrhea. Cholate pool size and synthetic rates were measured, and agerelated changes were observed. Preliminary observations were made on postnatal maturation and regulation of the enterohepatic circulation of cholic acid and the relationship to neonatal "physiologic" steatorrhea.

\section{MATERIALS AND METHODS}

\section{PATIENTS}

Time of Presentation. Ten patients, ages 3 months to 9 years (mean age, 44 months), studied between June 1977 and May 1979, comprised the study group (Table 1). At initial presentation, all patients except $D$. H. had chronic diarrhea lasting longer than one month which began in the first 3 months of life and required parenteral alimentation for nutritional support. D. H. had diarrhea and growth failure beginning at age one year. Diagnostic investigations included blood studies for assessment of hematologic, renal, and hepatic function; urine culture and catecholamine determination; sweat for chloride analysis; duodenal drainage for pancreatic enzyme assay, and bacteriologic and parasitic examination. Stool was examined for pathologic bacteria and parasites and for reducing substances by Clinitest. Quantitative fecal fat was measured on 72-hr collections. All patients had quantitative evidence of diarrhea compared to age-matched controls (greater than $100 \mathrm{~g}$ stool/day in infants), and several had reducing substances in their stools.

Peroral jejunal biopsy was abnormal in seven with findings varying from subvillous atrophy with increased cellular infiltration of lamina propria to a mild reduction in epithelial cell height with increased lamina propria cellularity. No specific etiology except the observed histologic abnormalities could be identified as the cause of the diarrhea.

Time of Study. Before the present study, patients with initially abnormal jejunal biopsies had repeat biopsies which showed either no abnormality or minimal abnormalities. The lone exception was M. S. who had round cell infiltration of the lamina propria and 
Table 1. Patient description

\begin{tabular}{|c|c|c|c|c|c|c|}
\hline Patient & Sex & Age & $\begin{array}{c}\text { Wt./height } \\
(\%)^{1}\end{array}$ & $\begin{array}{c}\text { Fecal wt. } \\
(\mathrm{g} / \mathrm{hr})\end{array}$ & $\begin{array}{c}\text { Coefficient of fat } \\
\text { excretion (\%) }\end{array}$ & Schilling test ${ }^{2}$ \\
\hline A. $\mathbf{T}$. & $\mathbf{M}$ & $3 \mathrm{mo}$. & $10 / 10$ & 54.1 & 1.0 & $+{ }^{3}$ \\
\hline R. B. & $\mathbf{M}$ & $6 \mathrm{mo}$ & $<5 /<5$ & 22.4 & 0.6 & ND \\
\hline F. B. & $\mathbf{M}$ & $10 \mathrm{mo}$ & $95 / 75$ & 153.1 & 2.7 & - \\
\hline B. J. & $\mathbf{M}$ & $16 \mathrm{mo}$ & $<5 /<5$ & 77.2 & 2.9 & ND \\
\hline B. $\mathbf{M}$. & $\mathbf{M}$ & $24 \mathrm{mo}$ & $25 / 25$ & 112.4 & 0.7 & + \\
\hline J. B. & $\mathbf{M}$ & $28 \mathrm{mo}$ & $25 /<5$ & 64.0 & 1.5 & + \\
\hline D. $\mathrm{H}$. & $\mathbf{M}$ & $34 \mathrm{mo}$. & $\ll 5 / \ll 5$ & 18.5 & 2.4 & - \\
\hline S. F. & $\mathbf{M}$ & $4 \mathrm{yr}$ & $\ll 5 / \ll 5$ & 42.9 & 3.0 & + \\
\hline N.P. & $\mathbf{F}$ & $5 \mathrm{yr}$ & $15 / 30$ & 59.7 & 3.5 & + \\
\hline M. S. & $\mathbf{M}$ & $9 \mathrm{yr}$ & $15 / 5$ & 531.8 & 3.0 & - \\
\hline
\end{tabular}

1 National Center for Health Statistics: NCHS growth charts, 1976.

2 With intrinsic factor.

${ }^{3}+=>8 \%$. ND, not done:,$-<8 \%$

mild epithelial cell shortening without significant villus height reduction. No child had gall bladder disease or clinical or biochemical evidence of liver disease at the time of the study. All patients were growing and receiving oral alimentation.

Patients were admitted to the General Clinical Research Center of the Cincinnati Children's Hospital 24 to $48 \mathrm{hr}$ prior to initiation of study and fed the same diet taken outside the hospital to ensure steady-state conditions. Stools were collected for $72 \mathrm{hr}$ after isotope administration. A Schilling test with intrinsic factor was performed on days 2 and 3 of the study (Table 1). Two children, F. B. and M. S., had diarrhea and abnormal vitamin B/2 absorption, whereas a third, D. H., had reduced vitamin B12 absorption alone. Since the study, all children have had no significant impairment of health except S. F. and D. H., who have persistent growth failure. This project was approved by the institutional Committee on Investigations Involving Human Subjects, and informed consent was obtained from subjects, when applicable, and their legal guardians.

\section{METHODS}

Cholic Acid Kinetics. These were estimated using the method of Lindstedt (17).

Procedure. After an overnight fast, a nasoduodenal tube was positioned under fluoroscopy. Five $\mu \mathrm{Ci}$ of $\left[\right.$ carboxyl- $\left.{ }^{14} \mathrm{C}\right] \mathrm{cholic}$ acid (New England Nuclear, Boston, MA; specific activity, 40 to $60 \mathrm{mCi} / \mathrm{mM}$ ) was administered IV in $10 \mathrm{cc}$ of $0.9 \% \mathrm{NaCl}$ solution, and the tubing was flushed. Three $\mathrm{hr}$ later, either sincalide (Kinevac) $(0.02 \mu \mathrm{g} / \mathrm{kg})$ given IV or 1.0 to $2.0 \mathrm{cc} 50 \% \mathrm{MgSO}_{4}$ administered intraduodenally were used to stimulate gall bladder contraction. The initial bile-rich duodenal fluid, collected on ice for $20 \mathrm{~min}$, represented the zero hr sample. Three $\mathrm{ml}$ were saved; and the remainder was returned via the tube to the patient so as to avoid excessive losses from the pool due to the sampling. The subjects were then allowed to eat during the remainder of the study with a 4-hr minimum fast prior to each subsequent collection. Samples were obtained in a similar manner at $+6,+24,+48$, and $+72 \mathrm{hr}$. The nasoduodenal tube was either left in place and tube position verified before each collection or reinserted prior to each collection under fluoroscopic control.

Analysis. Total bile acid concentration in duodenal bile was measured spectrophotofluorometrically according to a modification of the method of Murphy (19) as previously described. Qualitative distribution of bile acids was determined by gas-liquid chromatography (13). Two to five $\mu$ l of the methylated, acetylated samples were analyzed by gas-liquid chromatography (Hewlett Packard model 402) using a 6-foot glass column packed with 3\% OV-17 on Anachrom Q, mesh 100/120 (Analabs, Inc., New Haven, (T) at $300^{\circ} \mathrm{C}$ or $3 \%$ SP 2250 on Supelcoport, mesh $100 /$ 120 (Supelco, Inc., Bellefonte, PA) at $275^{\circ} \mathrm{C}$. The percentage of distribution of each bile acid was estimated by comparison to retention times and peak areas of standard reference compounds.
Thin-layer chromatographic separation of labeled compounds was performed as described by Heaton et al. (7). In a similar manner, the relative percentage of labeled compounds appearing as conjugates of glycine and taurine (glycine:taurine ratio) and the percentage of unconjugated cholic acid were estimated by thinlayer chromatography by determination of the distribution of radioactivity in eluted bands (10).

Calculations. Cholic acid specific activity was determined as previously described (8). The isotopic disappearance curve was determined by Wang model 700 Computer program. Pool size was calculated by dividing the dose of the injected isotope by bile acid specific activity determined in the zero-hr sample. Total bile salt pools were estimated by dividing the cholate pool size by the percentage of molar distribution of cholic acid in duodenal bile. In a similar fashion, chenodeoxycholate pool was estimated by multiplying the percentage of composition of duodenal bile acids attributed to chenodeoxycholate by the total pool size.

Other Methods. Fecal fat excretion was determined on $72-\mathrm{hr}$ collections by the method of van de Kamer et al. (23). Results are expressed as coefficient of fat excretion, e.g., $\frac{\text { fecal fat excretion }}{\text { dietary fat intake }}$ $\times 100 \%$. Schilling tests were performed by standard methods following administration of exogenous intrinsic factor with estimation of label excretion in 48-hr urine collections (20). Chemical determinations, including serum glutamic-oxaloacetic transaminase, serum glutamic-pyruvic transaminase, alkaline phosphatase, bilirubin, total protein, albumin, cholesterol, and triglycerides, were measured on a Dupont Automatic Clinical Analyzer. Results are expressed as mean \pm S.E. calculated by standard methods. Statistical significance between groups of patients was obtained by the analysis of variance. Intragroup correlations were calculated using the Pearson correlation coefficient (21).

\section{RESULTS}

Cholate pool size, synthetic rate, and fractional turnover rate corrected for body surface area for the study patients are listed in Table 2. Mean cholate pool was $1011 \mathrm{mg} / \mathrm{m}^{2}$, synthetic rate was $358 \mathrm{mg} / \mathrm{m}^{2} /$ day, and fractional turnover rate was 0.359 days $^{-1}$. The natural log of the specific activity of cholic acid was plotted against time for each study to allow calculation of the average correlation coefficient $(r=0.9545 \pm 0.009$; mean \pm S.E. $)$. The estimated chenodeoxycholate pool sizes, corrected for body surface area for the study patients, are similarly shown (Table 2); the mean value is $662 \mathrm{mg} / \mathrm{m}^{2}$.

The molar distribution of duodenal bile acid and the conjugation ratios found in our patients are shown and compared to those obtained in adults by Hofmann (11) in Table 3. The relative contribution of cholate to the total bile acid pool in infants and children is seemingly larger than in adults. Chenodeoxycholate comprises a fraction similar to the adult values. The reduced 
Table 2. Bile acid kinetics

\begin{tabular}{|c|c|c|c|c|c|}
\hline Patient & $\begin{array}{l}\text { Surface area } \\
\qquad\left(\mathrm{m}^{2}\right)\end{array}$ & $\begin{array}{l}\text { Cholate pool } \\
\left(\mathrm{mg} / \mathrm{m}^{2}\right)\end{array}$ & $\begin{array}{c}\text { Cholate fractional } \\
\text { turnover rate } \\
\left(\text { days }^{-1}\right)\end{array}$ & $\begin{array}{l}\text { Cholate synthesis } \\
\left(\mathrm{mg} / \mathrm{m}^{2} / \text { day }\right)\end{array}$ & $\begin{array}{c}\text { Chenodeoxycholate } \\
\text { pool } \\
\left(\mathrm{mg} / \mathrm{m}^{2}\right)\end{array}$ \\
\hline A. $T$. & 0.30 & 927 & 0.339 & 314 & 302 \\
\hline R. B. & 0.31 & 1228 & 0.531 & 652 & 908 \\
\hline F.B. & 0.52 & 965 & 0.389 & 376 & 1089 \\
\hline B. $\mathbf{J}$. & 0.47 & 610 & 0.515 & 314 & 594 \\
\hline B. $\mathbf{M}$. & 0.50 & 932 & 0.400 & 373 & 554 \\
\hline J. B. & 0.54 & 935 & 0.246 & 230 & 473 \\
\hline D. H. & 0.49 & 1189 & 0.582 & 692 & 563 \\
\hline S. F. & 0.52 & 999 & 0.309 & 309 & 575 \\
\hline N.P. & 0.77 & 1453 & 0.127 & 184 & 811 \\
\hline \multirow[t]{2}{*}{ M. S. } & 0.92 & 876 & 0.156 & 136 & 749 \\
\hline & & $1011 \pm 73^{1}$ & $0.359 \pm 0.049$ & $358 \pm 58$ & $662 \pm 72$ \\
\hline
\end{tabular}

\footnotetext{
${ }^{1}$ Mean \pm S.E.
}

Table 3. Duodenal bile composition

\begin{tabular}{|c|c|c|c|c|c|c|}
\hline \multirow[b]{2}{*}{ Patient } & \multicolumn{5}{|c|}{$\%$ molar distribution } & \multirow[b]{2}{*}{ Glycine:taurine } \\
\hline & Cholic acid & $\begin{array}{l}\text { Chenodeoxycholic } \\
\text { acid }\end{array}$ & Deoxycholic acid & Lithocholic acid & $\begin{array}{l}\text { Ursode- } \\
\text { oxycholic } \\
\text { acid }\end{array}$ & \\
\hline A. $T$. & 73.7 & 24.0 & $0^{1}$ & 0 & 2.2 & 3.81 \\
\hline R. B. & 57.5 & 42.5 & 0 & 0 & 0 & 1.77 \\
\hline F. B. & 45.2 & 51.0 & 1.7 & $\mathrm{TR}^{2}$ & 2.0 & 1.26 \\
\hline B. J. & 41.8 & 40.7 & 17.5 & TR & 0 & 5.40 \\
\hline B. $\mathbf{M}$. & 40.7 & 24.2 & 21.5 & 13.4 & 0 & 3.84 \\
\hline J. B. & 62.3 & 31.5 & 5.9 & 0 & 0 & 2.38 \\
\hline D. $\mathrm{H}$. & 57.4 & 27.2 & 14.1 & 1.3 & 0 & 7.62 \\
\hline S. F. & 49.9 & 28.7 & 17.4 & 2.5 & 0 & 7.07 \\
\hline N. P. & 59.3 & 33.1 & 7.3 & 0.2 & 0 & 1.77 \\
\hline \multirow[t]{2}{*}{ M. S. } & 53.2 & 43.5 & TR & 0 & 3.3 & 1.66 \\
\hline & $54.1 \pm 3.2^{3}$ & $34.6 \pm 2.9$ & $8.5 \pm 2.6$ & $1.7 \pm 1.3$ & & $3.66 \pm .74$ \\
\hline Adults (11) & 36 & 36 & 24 & 1.0 & $\mathrm{TR}$ & 3.0 \\
\hline
\end{tabular}

\footnotetext{
' 0 , none present.

${ }^{2}$ TR, trace amounts.

${ }^{3}$ Mean \pm S.E.
}

fraction of deoxycholate and lithocholate in children appeared to be balanced by an increase in cholate composition. Three children had ursodeoxycholic acid $(3 \alpha, 7 \beta$-dihydroxy- $5 \beta$-cholanoic acid $)$ in duodenal bile in quantities similar to those found in adults. Unconjugated cholate accounted for a minor proportion $(0.8 \%)$ of the total cholate concentration. The glycine:taurine conjugation ratio was higher in the study children than the 3:1 ratio usually reported in adults $(5,6)$.

Intragroup comparisons were calculated by cross-correlating observed cholate pool size, synthetic rate, fractional turnover rate, the glycine:taurine ratio, age, and surface area. Uncorrected cholate pool size correlated directly with age $(r=0.724 ; P=0.009)$ and surface area $(r=0.827 ; P=0.002)$. The fractional turnover rate varied inversely with age ( $r=-0.656 ; P=0.02)$, surface area $r=-0.642 ; P=0.023)$, and pool size $(r=-0.703 ; P=0.012)$ and directly with synthesis $(r=0.878 ; P<0.001)$. The glycine:taurine ratio was not dependent on any covariable.

\section{DISCUSSION}

The present study provides evidence that the enterohepatic circulation of cholate is intact in infants and children beyond age 3 months. Cholate pool size enlarged with increasing age and/or body surface area; fractional turnover rate varied inversely with age and body size. The cholate pool varied inversely with the fractional turnover rate. Although our patients were not normal in the strictest sense, all had recovered from chronic diarrhea in infancy and had no significant impairment of health related to gastrointestinal disease when assessed as long as 9 years after the onset of their illnesses. Therefore, findings regarding the enterohepatic circulation of cholate in our study patients appear applicable to normal infants and children.

Fat digestion may be severely disordered in the first months of life producing significant steatorrhea (4). Pancreatic lipase, although reduced in the term infant, may be present in sufficient quantities for normal lipolysis to occur during the first wk of life (30). Because bile salts play a central role in lipolysis and solubilization of lipolytic products, a reduction in intraluminal concentration below the minimum necessary for micelle formation, the critical micellar concentration, may seriously impair fat absorption. Bile salt pool sizes are reduced, and intraluminal concentrations are frequently below the critical micellar concentration (1.5 to $2.0 \mathrm{mM}$ ) in newborns, especially in premature infants. Watkins et al. $(27,28)$, using tetradeuterated cholate $\left(\left[2,2,4,4-{ }^{2} \mathrm{H}\right]\right.$ cholate), found cholate pools to be reduced to $88.5 \mathrm{mg} / \mathrm{m}^{2}$ in prematures and $290 \mathrm{mg} / \mathrm{m}^{2}$ in term newborns, accompanied by meal-stimulated intraluminal bile salt concentrations of 1.8 and $5.3 \mathrm{mM}$, respectively.

Cholate pools, when corrected for body surface, were found to be significantly larger $(P<0.001)$ in our patients than either the premature or term infants $(27,28)$. With an increase in cholate pool size, an age-related increase in meal-stimulated bile salt concentration follows because in five children, aged 5 months to 
9 years, the intraluminal concentration reached $7.1 \mathrm{mM}(8)$. Increased concentration of detergent micelles should facilitate lipolysis and fat solubilization and normalize fat absorption.

A significantly increased cholate synthetic rate was noted in our patients compared to both the premature $(P<0.001)$ and newborn $(P<0.02)$ infants $(27,28)$. No significant differences in the fractional turnover rates between these groups were found. These data suggest that the rapid increases in cholate pool sizes in the first wks of life must, in large part, be related to enhanced synthesis and increasing body size with a smaller contribution made by increased intestinal conservation of intraluminal bile acids.

Homeostatic mechanisms regulating pools and synthesis described in adults appear to operate in children. Pool sizes relate inversely to biliary secretion rate, recycling rates, and gall bladder emptying and directly relate to intestinal extraction of bile salts in adults. Consequently, pool size should be inversely related to the fractional turnover rate $(3,15,18)$. Little direct study of these aspects of biliary metabolism has been made in children. In the present study, the fractional turnover rate was the only determinant of pool size measured. An inverse relationship related to pool size was found, suggesting similar regulatory mechanisms in infants, children, and adults.

Rapid expansion of cholate pool size and synthesis rate may represent a homeostatic response to the rapid postnatal rise in serum and hepatic cholesterol as seen in guinea pigs studied by $\mathrm{Li}$ et al. (16). Pool enlargement improves intraluminal digestion and absorption and increases fecal sterol excretion, thereby providing adequate substrate for the developing organism while controlling the serum cholesterol concentration. Further characterization of the mechanisms responsible for postnatal changes in bile salt metabolism which occur in humans and confirmation of our preliminary observations need to be carried out through study of additional infants in the first months of life.

\section{REFERENCES AND NOTES}

1. Balistreri, W. F.. Partin, J. C., and Schubert, W. K.: Bile acid malabsorption-a consequence of terminal ileal dysfunction in intractable diarrhea of infancy. J. Pediatr., 89: 21 (1977).

2. Danzinger, R. G., Hofmann, A. F., Schoenfield, L. J., and Thistle, J. L.: Effect of oral chenodeoxycholic acid on bile acid kinetics and biliary lipid composition in women with cholelithiasis. J. Clin. Invest., 52: 2809 (1973).

3. Duane, W. C., and Hanson, R. C.: Role of gall bladder emptying and small bowel transit in regulation of bile acid pool size in man. J. Lab. Clin. Med., 92 : 858 (1978).

4. Fomon, S. J., Zeigler, E. E., Thomas, L. N., Jensen, R. C., and Filer, L. J., Jr.: Excretion of fat by normal full-term infants fed various milks and formulas. Am. J. Clin. Nutr., 23: 1299 (1970).

5. Garbutt. J. T., Heaton, K. W., Lack, L., and Tyor, M. P.: Increased ratios of glycine-to-taurine-conjugated bile salts in patients with ileal disorders. Gastroenterology, 56: 711 (1969).

6. Garbutt, J. T., Lack, L., and Tyor, M. P.: Physiological basis of alterations in the relative conjugation of bile acids with glycine and taurine. Am. J. Clin. Nutr., 24: 218 (1971).

7. Heaton, K. W., Austad, W. I., Lack, L., and Tyor, M. D.: Enterohepatic circulation of "C-labeled bile salts in disorders of the distal small bowel. Gastroenterology, 55: 5 (1968).

8. Heubi, J. E., Balistreri, W. F., Partin, J. C., Schubert, W. K., and McGraw, C. A.: Primary bile acid malabsorption: one cause of refractory infantile diarrhea. J. Pediatr., 94: 546 (1979).
9. Heubi, J. E., Fondacaro, J. D., Partin, J. C., and Balistreri, W. F.: Reduced ileal uptake of taurocholate in children with primary bile acid malabsorption. Clin. Res., 27; 454A (1979).

10. Hofmann, A. F.: Thin layer adsorption chromatography of free and conjugated bile acids on silicic acid. J. Lipid Res., 3: 127 (1962).

11. Hofmann, A. F.: The enterohepatic circulation of bile acids in man. Adv. Intern. Med., 21: 503 (1976).

12. Hofmann, A. F., and Hoffman, N. E.: Measurement of bile acid kinetics by isotope dilution in man. Gastroenterology, 67: 314 (1974).

13. Hofmann, A. F., and Poley, J. R.: Role of bile acid malabsorption in pathogenesis of diarrhea and steatorrhea in patients with ileal resection. Gastroenterology, 62: 918 (1972).

14. Kallner, M.: Bile acid kinetics in normal and hyperlipidemic man. Opusc. Med. Suppl., 35: 1 (1974).

15. LaRusso, N. F., Hoffman, N. E., Hofmann, A. F., Northfield, T. C., and Thistle, J. L.: Effect of primary bile acid ingestion on bile acid metabolism and biliary lipid secretion in gallstone patients. Gastroenterology, 69: 1301 (1975).

16. Li, J. R., Dinh, D. M., Ellefson, R. D., and Subbiah, M. T. R.: Sterol and bile acid metabolism during development. 3. Occurrence of neonatal hypercholesterolemia in guinea pig and its possible relation to bile acid pool. Metabolism. 28: 151 (1979).

17. Lindstedt, J.: The turnover of cholic acid in man: bile acids and steroids 51 . Acta Physiol. Scand., 40: 1 (1957).

18. Mok, H. Y. I., von Bergmann, K., and Grundy, S. M.: Regulation of pool size of bile acids in man. Gastroenterology, 73: 684 (1977).

19. Murphy, G. M., Billing, B. H., and Baron, D. N.: A fluorometric and enzymatic method for the estimation of serum total bile acids. J. Clin. Pathol., 23: 594 (1970).

20. Schilling, R. F.: Intrinsic factor studies. II. The effect of gastric juice on the urinary excretion of radioactivity after the oral administration of radioactive vitamin B12. J. Lab. Clin. Med., 42: 860 (1953).

21. Sokal, R. R., and Rohlf, F. J.: Biometry. pp. 223-226 (W. H. Freeman and Co., San Francisco, 1969).

22. Strandvik, B.: Bile acid metabolism in cholestasis of infancy. Opusc. Med. Suppl., 29: 1 (1973).

23. van de Kamer, J. H., ten Bokkel Huinink, H., and Wegers, H. A.: Rapid method for the determination of fat in feces. J. Biol. Chem., 177: 347 (1949).

24. Vlahcevic, Z. R., Bell, C. C., Jr., Buhac, I., Farrar, J. T., and Swell, L.: Diminished bile acid pool size in patients with gallstones. Gastroenterology, 59: 165 (1970).

25. Vlahcevic, Z. R., Buhac, I., Farrar, J. T., Bell, C. C., Jr., and Swell, L.: Bile acid metabolism in patients with cirrhosis. I. Kinetic aspects of cholic acid metabolism. Gastroenterology, 60: 491 (1971).

26. Vlahcevic, Z. R., Miller, J. R., Farrar, J. T., and Swell, L.: Kinetics and pool size of primary bile acids in man. Gastroenterology, 61: 85 (171).

27. Watkins, J. B., Ingall, D., Szczepanik, P. A., Klein, P. D., and Lester, R.: Bile salt metabolism in the newborn: measurement of pool size and synthesis by stable isotope technique. N. Engl. J. Med., 288: 431 (1973).

28. Watkins, J. B., Szczepanik, P., Gould, J. B., Klein, P., and Lester, R.: Bile salt metabolism in the human premature infant. Gastroenterology, 69: 706 (1975).

29. Watkins, J. B., Tercyak, A. M., Szczepanik, P., and Klein, P. D.: Bile salt kinetics in cystic fibrosis: influence of pancreatic enzyme replacement. Gastroenterology, 73: 1023 (1977).

30. Zoppi, G., Andreotti, G., Pajno-Ferrara, F., Njai, D. M., and Gaburro, D.: Exocrine pancreas function in premature and full-term neonates. Pediatr. Res., 6: 880 (1972).

31. The authors are indebted to Suzanne Madden, R.N. and the nurses and aides on the Clinical Research Center for technical assistance, Jessica Wise and Andrea Smith for secretarial assistance, L. Jonas for statistical analysis, and John C. Partin, M.D., and William K. Schubert, M.D., for advice in preparation of the manuscript.

32. Requests for reprints should be addressed to: James E. Heubi, M.D., Clinical Research Center, Children's Hospital Medical Center. Elland and Bethesda Avenues, Cincinnati, OH 45229 (USA).

33. This research was supported in part by USPHS Grant RR-00123 from the General Clinical Research Centers Branch, NIH, and the True Sisters of Ruth Lodge 18, Cincinnati, $\mathrm{OH}$.

34. Received for publication August 6, 1979.

35. Accepted for publication November 27, 1979. 